VONTADE GERAL E DECISÃO COLETIVA EM ROUSSEAU ${ }^{1}$

Cláudio Araújo Reis ${ }^{2}$

RESUMO: Nos termos rousseaunianos, a questão fundamental sobre o que devemos fazer coletivamente (ou seja, o problema da decisão coletiva) se traduz como a questão sobre como podemos conhecer a vontade geral. Só podemos responder adequadamente a essa questão, porém, se prestarmos atenção a uma duplicidade importante no conceito de vontade geral. Rousseau usa a mesma expressão para se referir a duas coisas diferentes: às próprias decisões coletivas, consubstanciadas nas leis (a vg-decisão), e ao padrão do bem comum, em certo sentido anterior e independente das decisões coletivas, servindo como referência para elas (a vg-padrão). A questão genérica sobre como podemos vir a conhecer a vontade geral, portanto, deve ser desdobrada em duas: Como podemos vir a conhecer a vg-decisão? e Como podemos vir a conhecer a vg-padrão? Este artigo pretende identificar os elementos centrais da resposta de Rousseau a essas duas questões, elementos esses que permitem discutir sobre o sentido da concepção rousseauniana de democracia.

PALAVRAS-CHAVE: Jean-Jacques Rousseau. Democracia. Decisão coletiva. Vontade geral.

Uma das ideias mais comumente associadas com a democracia é a de que, em um sistema democrático de governo, é o povo que tem a última

${ }^{1} \mathrm{O}$ presente texto retoma, modificando-as significativamente, algumas ideias desenvolvidas em uma breve comunicação apresentada em setembro de 2006, na Pontifícia Universidade Católica de São Paulo, por ocasião do Colóquio Internacional Religião e Política em Rousseau: em torno das Cartas escritas da montanha, sob o título "Vontade geral e deliberação"

${ }^{2}$ Departamento de Filosofia - Universidade de Brasília (UNB).E-mail: reis@unb.br 
palavra. A "voz do povo" é o que deveríamos ser capazes de escutar por trás de toda decisão relevante, em um sistema democrático. Mas, como podemos efetivamente reconhecer essa voz refletida nas decisões coletivas? Nosso objetivo, neste texto, é examinar alguns dos elementos centrais de uma resposta especialmente significativa a essa pergunta: a resposta rousseauniana, a partir do conceito de vontade geral. Para Rousseau, a voz do povo se faz ouvir por intermédio da vontade geral, que se consubstancia nas leis. Tudo gira, então, em torno da possibilidade de sabermos o que é a vontade geral.

Escolhendo partir de Rousseau e de sua ideia de vontade geral, uma primeira cautela logo se impõe. Reconhecidamente, o conceito de vontade geral é ao mesmo tempo um dos conceitos mais importantes da filosofia política do Cidadão de Genebra e uma de suas ideias mais fugidias. Mesmo sem a intenção de tentar capturar e fixar o significado essencial de "vontade geral" em Rousseau, queremos sugerir, como ponto de partida, que uma apreensão mais correta das implicações do conceito para a questão que interessa aqui - a questão sobre como podemos "ouvir a voz do povo" (ou, o que está sendo tomado aqui como equivalente, como podemos vir a conhecer a vontade geral) - passa pelo reconhecimento de uma oscilação fundamental, ao longo da argumentação rousseauniana, entre dois sentidos básicos de "vontade geral" - um sentido "substantivo" e outro "decisionista".

Talvez o sentido mais imediato do conceito de vontade geral, em Rousseau, apareça em conexão com a ideia de "corpo social" (ver, p. ex., CS, III, 361) $)^{3}$. Nessa conexão, a vontade geral não é outra coisa senão a "vontade do corpo político" entendido como "ser moral" - é a vontade do soberano. Como pessoa moral, o soberano teria uma vontade, em sentido análogo ao que ocorre com as pessoas naturais. Duas questões, porém, se impõem, com relação a essa primeira leitura - de resto, amplamente respaldada pelos textos de Rousseau: a primeira diz respeito à forma como devemos tomar e interpretar essa analogia (uma remissão aos desdobramentos da teoria dos seres morais em Hobbes e Puffendorf, em especial, se faz necessária para isso, mas não exploraremos essa via, neste texto); a segunda aponta para uma duplicidade que cerca o conceito de "vontade", que tanto pode referirse à faculdade de querer quanto ao ato de querer, que poderíamos, esse último, identificar com a decisão. Contudo, se o fato de um corpo moral (coletivo) tomar decisões não representa um problema especial, atribuir uma

${ }^{3}$ As referências aos textos de Rousseau remetem para a edição das Oeuvres complètes citada na bibliografia, com o volume em números romanos e as páginas em algarismos arábicos. Os títulos são referidos como siglas. Para uma lista das siglas utilizadas, ver a bibliografia. Os trechos citados, quando não houver menção em contrário, são por nós traduzidos. 
faculdade de querer à pessoa moral, que é o soberano, nos termos de Rousseau, não seria levar a analogia um pouco longe demais?

Além do mais, apesar da importância que possa ter esse sentido imediato, ele é insuficiente para explicar toda a extensão do uso que é feito da expressão "vontade geral", nos textos de Rousseau. Vale lembrar, por exemplo, que vontade geral e vontade particular muitas vezes se opõem no indivíduo, de modo que deve ser possível atribuir a vontade geral a outros sujeitos, que não apenas ao corpo social: também os cidadãos possuem uma "vontade geral", que não se confunde totalmente com sua vontade particular. Isso indica que a vontade geral não é apenas a faculdade de querer projetada no corpo social. Na verdade, na oposição entre vontade geral e vontade particular, não é, obviamente, no elemento "vontade" que se dá o conflito, mas naquilo que qualifica essa vontade ${ }^{4}$. E o que qualifica essa vontade é seu objeto: geral, em um caso, particular, no outro. Mais importante, portanto, do que o sujeito a que se atribui a vontade - à pessoa moral do soberano ou à pessoa natural dos cidadãos - é o objeto a que ela se refere. E esse objeto não é outro senão o interesse ou o bem comum.

Uma constante, ao longo do tratamento que dá Rousseau à ideia de vontade geral, é a sua associação com as noções de bem comum e de interesse geral (ou comum) ${ }^{5}$. Como lembra diversas vezes o autor do Contrat social, o que generaliza a vontade é, efetivamente, o interesse comum que une os membros da associação (ver CS, III, 374; e MG, III, 307). Se é assim, então a relação entre vontade geral e interesse comum é uma relação intrínseca, de tal modo que é impossível pensar a primeira sem considerar o segundo. Porém, dadas as dificuldades inerentes à noção de interesse ou bem comum, parece que perdemos mais do que ganhamos, ao fazer uma associação entre essa ideia e a noção de vontade geral. O que, afinal, é o interesse comum?

\footnotetext{
${ }^{4}$ Patrick Riley enfatiza, com razão, a importância da insistência de Rousseau na ideia de vontade, e não na mera generalidade. Isso é particularmente relevante quando se está discutindo o lugar da liberdade no pensamento político de Rousseau. Para a questão que examinamos, porém, a ideia de generalidade é mais importante do que a de vontade. Ver RILEY, 1982 e 2006. Ver também SHKLAR, 1969, p. 184, que Riley cita.

${ }^{5}$ Vamos assumir aqui que os adjetivos "geral" e "comum" (assim como "público") se equivalem, quando utilizados em expressões como "interesse comum", "necessidades comuns", "bem público" e outras equivalentes. Deixamos de lado a discussão sobre a possibilidade (ou mesmo a necessidade) de distinguirmos "geral" de "comum". Também não pomos uma distância significativa entre os conceitos de "bem comum" e "interesse comum". Sobre as relações entre os conceitos de vontade geral, interesse e bem comum, ver BERNARDI, 1998
} 
Um dos pontos-chave para a correta apreciação dos conceitos de bem e interesse comum é o de sua relação com as ideias de bem ou interesse particular. Geral e particular ou estão em oposição, ou estão em consonância. Rousseau mais de uma vez observa que sua reconstrução dos princípios do direito político promove a união entre interesse e justiça, entre aquilo que é vantajoso para o indivíduo e aquilo que é mais justo para a comunidade. Para o indivíduo, por conseguinte, deve sempre ser possível enxergar no interesse comum o seu próprio interesse - seja acreditando que o interesse comum é um agregado de que seu próprio interesse particular é um ingrediente (nesse caso, seu interesse particular é, em algum sentido, uma parte do interesse comum), seja considerando que o interesse comum sempre foi parte de seu próprio interesse particular (nesse outro caso, é o interesse comum que é visto como incluído no interesse particular). Queremos sugerir que Rousseau está mais próximo da segunda alternativa, de modo que, para ele, a conformidade do geral e do particular não deve ser pensada nos moldes da agregação, mas, sim, no da interseção. Rousseau lembra que o interesse geral se compõe daquilo que é comum aos diversos interesses (ver MG, III, 295; em CS, III, 371 aparece a caracterização da vontade geral como soma das diferenças; no mesmo registro, diz Rousseau, é o que há de comum entre os interesses que constitui o laço social - ver EP, III, 368). Dito de outra maneira, o interesse geral, que não está separado dos interesses particulares, é, de fato, constituído a partir desses últimos -, todavia, isso não deve ser pensado no modo da agregação ${ }^{6}$.

Essa ideia do bem ou interesse comum como interseção merece ser explorada. Ela pode, por exemplo, ajudar a esclarecer a distinção que faz Rousseau entre a vontade geral e a vontade de todos (com a vontade de todos remetendo, em algum sentido, para a ideia de agregação ${ }^{7}$ ). Permite também mostrar que as tensões entre interesse geral e interesse particular, entre vontade geral e vontade(s) particular(es), não podem jamais ser resolvidas com a supressão ou o apagamento do interesse particular, que pode, em princípio, ser tão variado quanto desejarmos. Não é, de fato, a pluralidade dos interesses particulares que põe um problema (na verdade, essa pluralidade é condição da política, reconhece o próprio Rousseau, dentro de certos limites), mas a ausência de interseção entre eles (e como garantir que essa interseção não seja um conjunto vazio é uma preocupação constante

\footnotetext{
${ }^{6}$ Não vamos aqui desenvolver essa tese, mas remetemos o leitor para as análises de John Rawls, que, em sua interpretação do Contrat social (retomando, a nosso ver, com resultado mais interessante, a tradicional chave kantiana de leitura do pensamento político rousseauniano), insiste igualmente em que o bem comum, tal como esse conceito está implicado pela filosofia política de Rousseau, não pode ser entendido em termos utilitaristas ou agregativos. Ver especialmente RAWLS, 2007, p. 229-230.
} 
de Rousseau). Por fim, essa ideia do interesse comum como interseção tem ainda um reflexo interessante sobre a importante questão da formação dos interesses, a que teremos oportunidade de retornar.

Em suma, melhor do que insistir em que a vontade geral é a vontade da pessoa moral, que é o soberano, é enfatizar a relação intrínseca que existe entre vontade geral e bem ou interesse comum, concebido como interseção dos interesses particulares. É verdade que Rousseau estabelece muito claramente, como condição para a manifestação da vontade geral, que não apenas seu objeto seja geral (e não há objeto mais geral do que o bem comum ou o interesse geral), mas também que seu sujeito seja o mais geral possível: ela tem de "partir" de todos. No entanto, essa insistência na generalidade do sujeito é mais uma maneira de enfatizar o compromisso com uma ideia forte de igualdade do que um reforço da ideia de atribuir a vontade geral à pessoa moral do soberano.

Vontade geral e interesse comum são termos que remetem um ao outro. Em especial, não é possível haver a primeira se não existe já, ainda que apenas parcialmente articulado, o segundo. Efetivamente, um dos interesses do esforço de descobrir qual é a vontade geral está em que isso é uma maneira de tentarmos justamente articular o interesse comum -e, com isso, enxergar mais nitidamente os laços que nos unem em uma comunidade política.

Essa proximidade entre as ideias de vontade geral e de interesse ou bem comum constitui, enfim, um dos pólos das oscilações de sentido que podem ser observadas com relação ao conceito de vontade geral nas obras de Rousseau. Rousseau ora apresenta a vontade geral como um padrão que deve orientar as decisões coletivas, ora como sendo, a vontade geral, uma maneira de nos referirmos às decisões coletivas elas mesmas. No primeiro sentido, a vontade geral, como padrão ou regra ${ }^{8}$, não é outra coisa senão o padrão do bem ou do interesse comum (em outras palavras, "vontade geral",

${ }^{7}$ Ver ALLEN, 1961, que associa a distinção entre vontade de todos e vontade geral a dois "modos de comportamento político", o agregativo e o associativo, empregando, de forma diferente, uma oposição que aparece efetivamente em Rousseau, no início do Contrat social, quando contrasta agregação e associação como duas formas diferentes de tentar dar unidade a uma coletividade. Ver também BARRY; REES, 1964, sobretudo p. 9-14, para uma reflexão esclarecedora sobre as relações entre as ideias de vontade geral e interesse geral.

${ }^{8}$ Rousseau diversas vezes refere-se à vontade geral como regra. Ver, p. ex., EP, III, 245, 247; MG, III, 286, 304; CS, III, 407. Mais ainda, a vontade geral é apontada como o padrão a que se deve olhar, quando falham as leis (toda a passagem sobre a "primeira regra da economia política", em EP, III, 250-251, é extremamente significativa). 
no sentido de padrão, é sinônimo de "bem comum" ou "interesse comum"). No segundo sentido, a vontade geral é a decisão (ou o conjunto de decisões ${ }^{9}$ ) tomada pelo soberano e fixada na forma da lei ${ }^{10}$.

Essa oscilação de sentido não implica inconsistência por parte de Rousseau. Na verdade, a reconstrução teórica que ele propõe da forma como são tomadas as decisões coletivas legítimas pede os dois sentidos - para os quais, no entanto, Rousseau usa a mesma expressão ${ }^{11}$. Vejamos mais de perto como isso se dá.

Chamaremos de vg-padrão e vg-decisão os dois sentidos entre os quais oscila a argumentação de Rousseau. Essa oscilação aparece claramente em uma célebre passagem do livro IV, que se encontra, muito significativamente, no capítulo sobre os sufrágios. A passagem diz o seguinte:

Quando se propõe uma lei na assembleia do povo, o que se lhes pergunta não é precisamente se eles aprovam a proposição ou se eles a rejeitam, mas se ela está conforme ou não à vontade geral, que é a deles. Cada um, ao dar seu sufrágio, diz sua opinião sobre isso e do cálculo das vozes se tira a declaração da vontade geral. (CS, III, 440/441).

\footnotetext{
${ }^{9}$ Gopal Sreenivasan propõe definir a vontade geral como o conjunto das decisões deliberativas de uma comunidade, tomadas sob determinadas condições. Ver SREENIVASAN, 2000, p. 553-554

${ }^{10}$ Vale a pena mencionar um terceiro possível sentido, que podemos associar à ideia de vontade geral, tal como aparece no Contrat social. Esse terceiro sentido possível tem relação com a duplicidade (a que já fiz alusão de passagem) implicada pelo conceito mesmo de "vontade", que pode se referir tanto a um poder ou a uma faculdade, quanto ao resultado da aplicação dessa faculdade Na sua leitura do Contrat social, John Rawls define vontade como uma "capacidade de razão deliberativa" (capacity for deliberative reason), capacidade que cada cidadão individualmente possui (não tem cabimento atribuir essa capacidade, afirma Rawls, à sociedade como um todo, ao "corpo político" ou à "pessoa moral"). A vontade geral, nesse sentido, seria uma "forma de razão deliberativa" - uma forma que implica um determinado "ponto de vista", justamente aquele ponto de vista que Rawls evoca em suas obras com a ideia de razão pública (ver RAWLS, 2007, p. 224ss e 229ss; Rawls chega a afirmar que a ideia de razão pública se origina com Rousseau). A vontade como resultado da aplicação da faculdade de querer é privilegiada, por exemplo, por Hobbes (vontade como último elo da cadeia de deliberação - vontade como ato, e não faculdade, de querer), e assim também aparece diversas vezes nos textos de Rousseau.

${ }^{11}$ Patrick Riley, em seus trabalhos sobre a ideia de vontade geral em Rousseau, chama a atenção para as dificuldades que o autor do Contrat social tem de enfrentar, por conta do "caráter instável e paradoxal" da ideia de volição. A distinção que faz Riley entre dois sentidos de vontade não é a mesma a qual enfatizamos aqui e, além do mais, o ponto aqui é menos ambicioso.
} 
Há duas referências à vontade geral, nessa passagem. Há, antes de mais nada, a referência à vg-padrão: o sufrágio exprime a opinião do cidadão (e não sua preferência, o que é interessante e significativo; voltaremos a isso) sobre a conformidade da proposição com a vontade geral (com o bem comum). Mas há também uma referência à vg-decisão: após a apuração dos votos, declara-se a vontade geral. Note-se que, no primeiro caso, parece que a vontade geral preexiste ao procedimento: para votar, devo consultar a vontade geral. No segundo caso, a vontade geral parece ser resultado do processo: após o voto, declara-se a vontade geral. Note-se ainda, uma vez mais, que não se quer aqui encontrar uma contradição, embora exista algum grau de ambiguidade, dado o uso diferente da mesma expressão ambiguidade que, aliás, bem poderia pertencer à própria natureza do procedimento do sufrágio. É para essa ambiguidade - e para o que ela pode revelar sobre o procedimento - que se quer aqui chamar a atenção.

Voltemos ao trecho citado. O que se pede do cidadão, enfim, é que dê sua opinião sobre o que é melhor para o corpo social. Genericamente, o que é melhor para o corpo social é que o bem comum, que (se existe comunidade) necessariamente existe, seja promovido. Dar sua opinião, nesse caso, significa dar uma interpretação do que seja, no caso particular, o bem comum (ou de qual seja a relação do caso particular com o interesse geral $)^{12}$. Isso implica, naturalmente, que esse bem comum seja, em alguma medida, previamente conhecido. Uma articulação, em algum sentido, do que seja esse bem ou interesse comum tem de existir. Vale insistir: o processo do sufrágio não é um processo em que o bem comum vai ser "criado" ou "construído" (já que o bem comum, como padrão, preexiste ao processo), nem é completamente um procedimento de descoberta (o sufrágio, pelo menos no sentido mais forte de deliberação sobre os fins, se parece mais com um processo de interpretação do que de descoberta; sua conclusão é, se quisermos, uma nova interpretação do que seja o bem comum). Nesse processo, o que ocorre, no máximo, é um refinamento da percepção, que os cidadãos já tinham anteriormente, do seu próprio interesse comum. O que resultará do processo, em termos de uma decisão, será apenas uma precisão do que seja o bem comum. Antes do procedimento - e como garantia para sua confiabilidade -

12 Poderíamos aqui introduzir uma complicação: haveria uma diferença entre deliberar diretamente sobre o que é o bem comum (isso seria uma espécie de "deliberação" sobre os fins, se quisermos), propondo-se, eventualmente, uma nova interpretação ou articulação do que seja esse bem comum, e deliberar sobre os meios mais aptos a fazer avançar o bem comum? Nos termos radicalmente democráticos propostos por Rousseau, o primeiro tipo de deliberação é privilégio inalienável do soberano, enquanto o segundo pode ser, em alguns casos, talvez, também atribuição do governo, responsável pela escolha dos melhores meios para realizar os fins que se pôs a sociedade. 
tem já de existir uma concepção minimamente articulada do que seja o bem comum, que entrará, justamente, na forma de um padrão a ser consultado, como uma parte constitutiva do procedimento.

Introduzamos agora o problema de como podemos responder à questão sobre o que devemos, coletivamente, fazer - ou seja, a questão sobre qual é nossa vontade geral. Ora, se estamos falando da vg-decisão, isso não é mais do que o resultado de um determinado procedimento - o procedimento do sufrágio, por exemplo -, realizado sob determinadas condições, que nos cabe em seguida examinar. A vg-decisão não é outra coisa senão a declaração do resultado do procedimento do sufrágio. O problema é que, entre as condições que tornam confiável o processo, está justamente que já tenhamos algum conhecimento do que seja nossa vontade geral (compreendida como o padrão a que devemos submeter nossa opinião no procedimento de sufrágio) - ou seja, conhecer a vg-decisão supõe que já conheçamos a vg-padrão.

Esse descompasso entre a vg-decisão e a vg-padrão ajuda a explicar alguns movimentos importantes da argumentação de Rousseau, jogando luz sobre alguns aspectos significativos de seu pensamento político. Vejamos isso mais de perto.

Se a vontade geral é, em algum sentido, a vontade da comunidade como um todo (é a vontade do soberano ou, se quisermos, do povo) e se a vontade geral está sempre voltada necessariamente para o bem ou o interesse comum, então faz todo sentido, como afirma Rousseau, que o povo sempre queira o bem (isso, naturalmente, é uma versão do antigo princípio de que não se pode desejar senão sub specie boni). No Discours sur l'économie politique, Rousseau chega a mencionar o velho adágio que associa a voz do povo à voz de Deus (EP, III, 246). A vontade geral (como vontade do povo, como voz de Deus) é sempre, por definição, reta, por estar sempre voltada para o bem comum. Nessa medida, ela tem, efetivamente, uma tendência à infalibilidade, que Rousseau lhe atribui no capítulo III do Livro II do Contrat social. O problema é que entre a vontade geral e as "deliberações públicas" há uma distância - a distância que existe, justamente, entre a vg-decisão e a vg-padrão. As decisões do povo seriam sempre boas, se o que é bom fosse identificado, simplesmente, com essas mesmas decisões. Mas há um padrão, independente das decisões, a ser respeitado. Se há uma garantia, inscrita na ideia mesma de vontade geral como atrelada ao bem comum, de que ela será sempre reta, não há a mesma garantia, quando agora tratamos da vontade geral como decisão - porque a retidão dessa decisão depende, entre outras coisas, de um juízo (que nem sempre será reto, já que depende do conhecimento do padrão e que desse conhecimento não temos ainda nenhuma garantia). 
Portanto, se a questão sobre o que devemos fazer coletivamente equivale à questão sobre como chegamos a conhecer a vontade geral (ou como podemos ouvir a voz do povo), então não há uma resposta unívoca: devemos respondê-la atentando para a diferença - e a distância - que existe entre a vg-padrão e a vg-decisão.

Resumindo, para podermos seguir adiante, nos termos rousseaunianos, a questão fundamental sobre o que devemos fazer coletivamente (ou seja, o problema da decisão coletiva) se traduz como a questão sobre como podemos conhecer a vontade geral. Só podemos responder adequadamente a essa questão, porém, se prestarmos atenção a uma duplicidade importante, no conceito de vontade geral. Rousseau usa a mesma expressão para se referir a dois aspectos diferentes: às próprias decisões coletivas, consubstanciadas nas leis (que estou chamando de vg-decisão), e ao padrão do bem comum, em certo sentido anterior e independente das decisões coletivas, servindo como referência para elas (que chamamos de vg-padrão). A questão geral sobre como podemos vir a conhecer a vontade geral, portanto, deve ser desdobrada em duas: Como podemos vir a conhecer a vg-decisão? e Como podemos vir a conhecer a vg-padrão?

\section{Conhecendo a vg-decisão}

Rousseau procura responder, pelo menos em termos gerais, à questão sobre como conhecemos a vg-decisão, que é, em suma, a decisão que se segue a um procedimento de deliberação coletiva (o sufrágio), realizado sob determinadas condições e restrições. Vamos agora nos deter na análise das condições que devem ser satisfeitas pelo procedimento do sufrágio, para que resulte de forma confiável na declaração da vontade geral (ou seja, na vg-decisão). Essas condições são expostas por Rousseau ao longo de todo o Contrat social, e devem incluir necessariamente pelo menos as seguintes ${ }^{13}$ :

\footnotetext{
${ }^{13}$ Ressalte-se que essas condições são necessárias, embora não sejam suficientes. Nesta lista, aparecem pelo menos as principais condições mencionadas e examinadas por Rousseau. Outras poderiam talvez ser lembradas e acrescidas (por exemplo, talvez devêssemos incluir como condição necessária a ausência de desigualdades extremas). Se jamais poderemos chegar a um conjunto de condições suficientes, dada a complexidade da situação política, é uma questão permanentemente aberta. Ao tratar das condições ou das restrições às deliberações públicas, talvez fosse necessário dizer algo também a respeito de uma questão prévia ao sufrágio, que é a questão da iniciativa legislativa e, mais geralmente, a questão da definição da agenda ou da pauta de deliberações, o que remete, nos termos de Rousseau, à questão geral das relações entre o governo e o soberano, entre o corpo de magistrados responsáveis pela administração pública e o corpo soberano,
} 
- A matéria sobre a qual se delibera é absolutamente geral;

- Os efeitos da matéria são perfeitamente gerais;

- Todos os cidadãos participam do processo de tomada de decisão;

- Há clareza, por parte de cada um, do que seja a vg-padrão;

- Cada cidadão está suficientemente informado sobre a proposição apresentada;

- Cada indivíduo pensa e delibera por si mesmo, ouvindo a voz da consciência;

- Cada indivíduo manifesta sua opinião sobre a conformidade ou não da proposta ao interesse comum (à vg-padrão).

- Vamos agora comentar brevemente essas condições, tentando desdobrar parte de suas implicações.

A) As três primeiras condições correspondem à generalidade da lei (que deve partir de todos, se aplicar a todos e tratar de matéria que diz respeito a todos). A terceira condição, em particular, é interessante. Lembremos que Rousseau é bastante enfático no que diz respeito à necessidade de incluir a todos no processo: a unanimidade da decisão, embora desejável ${ }^{14}$, não é necessária; mas a exclusão de uma única voz do processo de tomada de decisão (mesmo que a decisão venha a ser finalmente tomada por maioria) pode pôr tudo a perder.

Aqui caberiam algumas reflexões em torno das questões da universalização do sufrágio e, especialmente, das relações entre maioria e unanimidade ${ }^{15}$. Sem condições de explorar a questão em toda a sua extensão, gostaria aqui de ressaltar apenas dois pontos. O primeiro diz respeito à desejabilidade da unanimidade. O segundo, à confiabilidade da maioria.

formado pelo conjunto dos cidadãos. Rousseau trata brevemente do problema, nos capítulos XIII e XVIII do livro III do Contrat social (III, 426-427, 435-436; evoca ainda, no livro IV, cap. IV, os comícios romanos). Sobre esse ponto, ver PUTTERMAN, 2003, 2005 e SCOTT, 2005.

${ }^{14}$ Rousseau não deixa dúvida quanto a essa desejabilidade. Ver, p. ex., CS, III, 439: "Quanto mais reina o acordo em uma assembleia, ou seja, quanto mais as opiniões se aproximam da unanimidade, tanto mais também é a vontade geral dominante; mas os longos debates, as dissensões, o tumulto anunciam a ascendência dos interesses particulares e o declínio do Estado". A unanimidade é necessária, certamente, em alguns casos fundamentais - o pacto, por exemplo, implica a unanimidade -, mas estou me referindo aqui às decisões coletivas particulares que o corpo político é obrigado a tomar, ao longo de sua existência.

${ }^{15}$ Desenvolver adequadamente esse tópico não é possível no espaço restrito deste artigo. Para uma discussão mais ampla, remetemos o leitor ao célebre ensaio de Bernard Manin sobre a deliberação (MANIN, 1985) e à argumentação interessante, embora não sem problemas, de Pierre Favre (FAVRE, 1976). 
Como já foi lembrado acima, para Rousseau, a unanimidade não é necessária para as decisões coletivas - o que não impede que permaneça como um ideal desejável ${ }^{16}$. Dizer que a unanimidade não é necessária para as decisões coletivas significa dizer que não é necessária para sua legitimidade. Decisões majoritárias, desde que respeitadas as condições em que o sufrágio é confiável, são legítimas. No entanto, dada a desconfiança que Rousseau frequentemente manifesta em relação aos efeitos das dissensões e das divisões, a condição de unanimidade parece desejável para a estabilidade de qualquer comunidade política. Esse é um ponto relevante, que precisará ser levado em conta, quando formos tratar da questão sobre como podemos conhecer a vg-padrão.

A condição de unanimidade pode ser definida como a situação em que os desacordos desaparecem (ou a situação em que os desacordos encontram uma solução). Essa (dis)solução do desacordo é, por sua vez, um dos objetivos fundamentais de um processo de tomada de decisão coletiva, como o sufrágio. Ora, o processo de sufrágio, tal como o concebe Rousseau, implica a aceitação da regra da maioria. Porém, como pode o recurso à maioria dissolver o desacordo? Já a mera menção à maioria significa a existência de uma minoria discordante. Parece haver, portanto, uma tensão entre o objetivo da busca do consenso (da unanimidade como dissolução do desacordo) e o recurso à regra da maioria como parte do procedimento de tomada de decisão. Rousseau resolve isso insistindo no caráter epistêmico do sufrágio: dadas as condições em que o processo é conduzido, o cidadão cujo voto é vencido pela maioria deve concluir que sua opinião sobre o que é a vontade geral (opinião expressa pelo seu voto) é simplesmente errada. Sua submissão à opinião da maioria, nesse caso e nessas condições, não representa violação da condição de que permaneça "tão livre quanto antes" (ou seja, submetendose à maioria, a minoria não abre mão da autonomia que a comunidade política está obrigada a preservar). Submeter-se à maioria, nesse caso, não seria diferente de submeter-se à força da verdade. Isso, naturalmente, supõe que se possa confiar em que a maioria vai ser mais apta a ver onde está a verdade sobre a vontade geral. Rousseau não desenvolveu esse ponto, explicitamente, mas tudo isso é extremamente relevante no que tange à questão sobre como podemos conhecer a vontade geral ${ }^{17}$.

\footnotetext{
${ }^{16}$ Pode-se salientar que o ideal não é exatamente o da unanimidade, mas o do consenso. Da forma como a estamos tomando aqui, a ideia de unanimidade como ideal não se distingue da ideia da busca do consenso (ou de um tipo de consenso) nas decisões coletivas. Ver, sobre a ideia de consenso em Rousseau, GRAHAM, 1970.

${ }^{17}$ As leituras que aproximam a concepção rousseauniana do sufrágio das ideias que Condorcet procurou formalizar, no que ficou conhecido como "teorema do júri", procuram
} 
B) A quarta condição é muito importante: sem garantias de que os cidadãos sejam capazes de ver com clareza o que seja o bem comum, a confiabilidade do processo cai vertiginosamente. Não obstante, como se trata, aqui, da questão sobre como podemos conhecer a vg-padrão, deixaremos para analisar essa condição na próxima seção.

C) A quinta e a sexta condições são formuladas por Rousseau, no contexto de sua rejeição das facções. Esse é um ponto interessante, que diz muito sobre a maneira como Rousseau pensa que podemos vir a conhecer a vg-decisão. A passagem é muito conhecida, mas vale a pena citá-la:

\begin{abstract}
Há frequentemente muita diferença entre a vontade de todos e a vontade geral; esta diz respeito apenas ao interesse comum, a outra se refere ao interesse privado e é apenas a soma das vontades particulares: mas tirai dessas mesmas vontades os mais e os menos que se destroem mutuamente, resta por soma das diferenças a vontade geral. Se, quando o povo suficientemente informado delibera, não havendo entre eles nenhuma comunicação, do grande número de pequenas diferenças resultaria sempre a vontade geral e a deliberação seria sempre boa. Mas quando se fazem facções, associações parciais em detrimento da grande, a vontade de cada uma dessas associações torna-se geral em relação aos seus membros e particular com relação ao Estado; pode-se dizer então que não haverá tantos votantes quanto há homens, mas somente quanto há associações. As diferenças tornam-se menos numerosas e dão um resultado menos geral. Enfim, quando uma dessas associações é tão grande que domina todas as outras, não tereis mais como resultado uma soma de pequenas diferenças, mas uma diferença única; então não há mais vontade geral e a opinião que ganha é apenas uma opinião particular. (ROUSSEAU, 1964, p. 371).
\end{abstract}

Essa passagem, muito rica, é uma das mostras mais eloquentes da perspicácia política do cidadão de Genebra. Não cabe aqui explorar toda sua riqueza; contudo, gostaríamos de fazer referência aos dois pontos destacados acima, como as condições 5 e 6, na lista que apresentamos. Que o povo deva estar suficientemente informado é autoexplicativo. Essa informação diz respeito, naturalmente, aos detalhes do caso particular a ser deliberado, mas concerne também ao conhecimento que têm os cidadãos

justamente desenvolver o que Rousseau deixou implícito. Ver, especialmente, GROFMAN; FELD, 1988. Estlund faz uma análise crítica interessante tanto dessa leitura condorcetiana de Rousseau quanto, em geral, da concepção epistêmica do sufrágio proposta por Rousseau: ver ESTLUND et al., 1989, e ESTLUND, 2008. Ver também as reflexões de G. Gaus sobre algumas versões do populismo, em GAUS, 1997. Para uma leitura diferente (crítica da leitura epistêmica) da posição de Rousseau sobre regras de decisão, ver SCHWARTZBERG, 2008. 
do padrão do bem comum, ou seja, da regra de justiça, que é a vg-padrão. Vale lembrar, mais uma vez, que o procedimento do sufrágio, para Rousseau, tem um caráter epistêmico: trata-se de descobrir qual é a melhor interpretação sobre o que é mais adequado, segundo o padrão do bem comum. Mais misteriosa é a afirmação de que a deliberação deve ocorrer sem que haja comunicação entre os cidadãos. Essa assertiva de Rousseau é frequentemente interpretada à luz do que se segue, no texto do Contrat social, a respeito das facções (e há quem veja aqui mais uma evidência da proximidade das ideias de Rousseau da formalização proposta por Condorcet, no que se costuma chamar de "teorema do júri"). Entretanto, talvez ela deva ser interpretada literalmente: a ideia é que, uma vez informado, cada cidadão dá sua opinião individualmente. O processo deliberativo, segundo Rousseau, é menos uma troca pública e coletiva de razões e argumentações do que uma consulta individual à consciência. ${ }^{18}$ Ouvir a voz da consciência, que é um sentimento e está sempre voltada para o bem, é o ponto fundamental. Lembremos que mais de uma vez Rousseau explicita sua falta de gosto pelos debates, pelas discussões públicas. O processo pelo qual se chega à declaração da vontade geral (pelo qual tomamos uma decisão coletiva) não é essencialmente um processo de troca de razões nem, muito menos, um processo de barganha, de negociação, de acomodação de interesses (o que tende, como bem viu Rousseau, a ser agravado por uma política de facções, de partidos, que fatalmente dirigem o jogo político em direção à competição e não à cooperação).

D) Por fim, a sétima condição aponta para uma característica interessante - e importante - da teoria democrática rousseauniana: é que essa teoria, ao incluir uma interpretação epistêmica do voto, implica uma concepção epistêmica de democracia. Dado o interesse e a relevância desse ponto, é imperioso determos nossa atenção nele, por um momento.

Em um texto de 1986, Joshua Cohen esboça uma concepção que batizou de "populismo epistêmico", em resposta às críticas dirigidas por William Riker ao "populismo" em geral (entendido, genericamente, como a crença de que procedimentos democráticos servem para exprimir a vontade geral ou a vontade do povo ${ }^{19}$. O "populismo epistêmico" seria uma forma de populismo imune às críticas de Riker - e, como reconhece Cohen, em seu texto, deve muito a uma determinada interpretação dos argumentos rousseaunianos sobre a vontade geral.

\footnotetext{
${ }^{18}$ Neste ponto, uma aproximação da teoria rousseauniana da consciência e da teoria da vontade geral seria muito esclarecedora. Não faremos isso aqui, mas, para uma exploração parcial da teoria rousseauniana da consciência, remetemos a Reis, 2005, sobretudo cap. IV, seção 2, e às referências ali utilizadas.

${ }^{19}$ COHEN, 1986a; RIKER, 1982
} 
No centro de uma concepção epistêmica de democracia está, segundo Cohen, uma interpretação epistêmica do voto. Cohen identifica três elementos que constituem uma tal interpretação:

- Um padrão independente do que sejam decisões corretas, ou seja, uma concepção do que seja o bem comum que é independente do consenso real e do resultado dos votos;

- Uma concepção cognitiva do voto, isto é, a crença de que votos exprimem opiniões (e não preferências) sobre quais decisões são corretas, de acordo com o padrão independente; e

- Uma concepção do processo de tomada de decisões como um procedimento de ajuste das crenças, ajuste esse que é conduzido, pelo menos em parte, à luz da evidência sobre a resposta correta que é fornecida pelas crenças dos outros ${ }^{20}$.

O populista epistêmico, em particular, vai identificar o padrão independente com uma "vontade geral" ou "popular". Ter uma vontade geral implica, entre outras coisas, segundo Cohen, compartilhar uma concepção do bem comum, que, portanto, vai funcionar como o padrão de correção para as decisões. Não é difícil reconhecer aqui a estrutura da descrição rousseauniana do procedimento do sufrágio.

Como é claro, essa reconstrução epistêmica do procedimento do voto só funciona na medida em que exista, independentemente (e anteriormente) a qualquer decisão coletiva, essa vontade geral (que chamamos vg-padrão), identificável com uma concepção do bem comum. Antes de voltarmos à questão sobre como podemos conhecer esse padrão, condição necessária para todas as tomadas de decisões coletivas, talvez valha a pena tentarmos responder outra pergunta: o que significa, exatamente, compartilhar uma concepção do bem comum?

Patrick Riley, em sua interpretação de Rousseau, identifica, no cerne do pensamento político do genebrino, um núcleo de instabilidade e de paradoxo, associado com o uso que faz Rousseau da noção de "vontade". Para Riley, o conceito de vontade geral, tal como aparece em Rousseau, é "um amálgama de duas tradições do pensamento político extremamente importantes, que podem ser chamadas coesão antiga [ancient cohesiveness] e voluntarismo moderno" ${ }^{21}$. Isso teria uma série de reflexos importantes, ao

${ }^{21}$ RILEY, 1982, p. 99. Vários leitores de Rousseau destacam a convivência, de resto bastante óbvia, em sua obra não apenas de temas antigos e modernos, mas, também, de um "espírito" antigo, lado a lado com esquemas modernos de pensamento, como o argumento contratualista.
} 
longo da concepção política defendida por Rousseau - e, em particular, poderia explicar uma certa "tonalidade" de seu pensamento político, que não poucos já quiseram identificar com uma tendência "totalitária"22. Esse amálgama implica igualmente uma dupla possibilidade de responder à questão que colocamos acima: o que significa, exatamente, compartilhar uma concepção do bem comum?

Riley vê Rousseau como defendendo o que chama de uma "moralidade do bem comum":

[O] que Rousseau admirava na sociedade antiga não é realmente uma vontade geral, mas uma moralidade política do bem comum, na qual a vontade individual não é suprimida, mas simplesmente não aparece em contraste com, ou erguendo pretensões de direito contra, a sociedade. O que dava à política antiga sua unidade não era a convergência de muitas vontades em pontos centrais de interesse comum, mas, antes, um idioma moral no qual a socialização extrema era natural e no qual havia pouco espaço para uma noção de vontade e artifício. (RILEY, 1982, p. 113). ${ }^{23}$

Mesmo que queiramos evitar chegar ao extremo da acusação de inconsistência, é difícil ignorar a ambiguidade que cerca o pensamento de Rousseau, em função dessa sua dupla fidelidade, aos ideais antigos de coesão social e modernos de igualdade e liberdade. A partir de cada um desses ideais, o significado de "compartilhar uma moralidade do bem comum" pode significar uma coisa diferente. Da perspectiva antiga, representa um sentido de comunidade que dificilmente se deixa capturar completamente do ponto de vista do individualismo moderno. Da perspectiva moderna, é difícil ignorar o que Rawls chamou de "fato do pluralismo razoável", que põe algumas dificuldades para uma noção de moralidade do bem comum compartilhada.

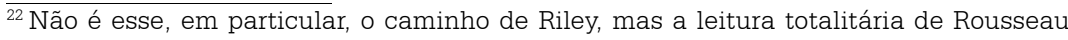
muitas vezes também aponta para os mesmos elementos que Riley denuncia no "amálgama" de tradições que identifica no pensamento rousseauniano. Em registro diferente (e em uma escala bem mais ampla e ambiciosa), mas apontando na mesma direção, Louis Dumont identifica um núcleo problemático no pensamento de Rousseau, a partir também de uma espécie de "amálgama" entre valores individualistas e holistas, coisa que associa igualmente ao fenômeno totalitário. Ver, p. ex., DUMONT, 1966, p. 301; DUMONT, 1977, p. 21-22; DUMONT, 1983, p. 102.

${ }^{23}$ Joshua Cohen (COHEN, 1986b) dá a Riley uma resposta que tem elementos interessantes. No entanto, a interpretação proposta por Cohen, assim como a que propõe Rawls, que transformam Rousseau em uma espécie de profeta do liberalismo político, tal como o define Rawls, desconsidera muito rapidamente o que a visão política e social do genebrino deve à sua nostalgia da cidade antiga e, mais ainda, à sua visão de si mesmo e do seu papel como filósofo, e, em geral, à sua concepção terapêutica de filosofia.
} 
O fato do pluralismo (ou do desacordo) razoável, certamente, não impede que falemos em algum sentido de bem comum - e a própria teoria da justiça de Rawls pode ser um exemplo disso ${ }^{24}$. Todavia, esse "bem comum" de que poderíamos tratar, dessa perspectiva moderna, é bem menos abrangente e substantivo, por assim dizer, do que o "bem comum" de que fala Rousseau. Reduzi-lo a uma concepção de justiça, nos termos do liberalismo moderno, seria esvaziá-lo de parte de seu sentido.

Compartilhar uma concepção do bem comum é um dos principais ingredientes que fazem de um povo, um povo. Isso inclui o vasto e impreciso domínio dos moeurs (o qual, aliás, é terreno privilegiado para a ação do Legislador), assim como tudo aquilo que cai sob o alcance do amour de la patrie. É nesse sentido, pleno de alusões antigas à virtude de Esparta e da Roma republicana, que deve ser tomado o que Rousseau entende por "compartilhar uma noção de bem comum". É nesses termos substantivos que deve ser compreendido o padrão exigido pela concepção epistêmica do sufrágio em Rousseau. E esse padrão não é outra coisa senão a vg-padrão.

Enfim, tomada nessas condições examinadas acima, a decisão coletiva exprime a vontade geral. Respeitado esse procedimento confiável, aquele que tem seu voto vencido pode reconhecer sem medo que sua derrota não significa que seu interesse foi desconsiderado ou mesmo prejudicado (afinal, no processo, está inscrita a garantia de que o interesse comum, que é também nosso interesse, está sendo promovido), mas apenas que sua opinião sobre o que é a vontade geral estava errada. Satisfeitas essas condições, os mais e os menos que distinguem as vontades particulares são mutuamente anulados e o que resta da soma das diferenças é a vontade geral - para lembrar uma das mais famosas formulações rousseaunianas a respeito da vontade geral.

\footnotetext{
${ }^{24}$ Como sugerimos, o conteúdo da vontade geral é uma determinada concepção do que seja o bem comum, que deve orientar, na forma de um padrão, as decisões coletivas. Cohen (1986a), por sua vez, sugere que a teoria da justiça como equidade de Rawls poderia ser uma dessas concepções de bem, constituindo, assim, o conteúdo da vontade geral (Cohen não o faz, mas poderíamos pensar ainda que seria interessante traçar um paralelo entre a ideia do consenso por interseção (ou consenso sobreposto), em Rawls, e a ideia rousseauniana do bem comum como interseção, que exploramos mais acima). Essa sugestão de Cohen é perfeitamente plausível, mas esconde o fato de que, no liberalismo político contemporâneo, a esperança de conseguir um consenso em torno de uma teoria da justiça só se dá ao preço de separar fortemente as questões ("abrangentes") sobre o bem, fadadas ao desacordo razoável permanente, das questões mais restritas sobre o justo. Essa distinção não pode ser projetada sobre Rousseau.
} 
Contudo, resta ainda que examinemos uma das condições fundamentais para que o procedimento do sufrágio resulte na declaração da vontade geral: a condição de que é preciso conhecer a vg-padrão. Sabemos que, para vir a conhecer, com alguma confiabilidade, a vg-decisão, precisamos conhecer a vg-padrão. Mas como podemos vir a conhecer a vg-padrão?

\section{Conhecendo a vg-padrão}

Como foi sugerido, a vg-padrão não é outra coisa senão o bem ou interesse comum. Aquilo que é nossa vontade coletiva, aquilo que queremos coletivamente é, nos termos mais gerais que podemos pensar, o nosso bem comum ou coletivo. Note-se, preliminarmente, uma ambiguidade que pode ter desdobramentos significativos: trata-se do que efetivamente desejamos (ou seja, o conjunto dos fins que queremos, com nosso esforço conjunto, alcançar) ou do que deveríamos desejar? Por se tratar de uma regra, a vgpadrão tem necessariamente um sentido normativo: sua orientação pode, eventualmente, ir contra aquilo que efetivamente desejamos (a vontade geral não se identifica com a vontade de todos, como sabemos).

Relacionada a isso surge a questão sobre qual é o "conteúdo", por assim dizer, do bem comum. Em termos gerais, apenas duas coisas talvez possam ser ditas para responder a essa pergunta. Primeiro, que seja lá o que mais for desejado, sempre se deseja a preservação do corpo político. Esse é o conteúdo mínimo da ideia de bem comum: é um interesse compartilhado por todos que subsistam ao longo do tempo as condições que tornam possível a comunidade de cidadãos livres e iguais (e como quem quer o fim quer também os meios necessários para realizá-lo, também podemos incluir esses últimos, genericamente considerados, na nossa ideia de bem comum). Segundo, que todo o resto que entra na nossa ideia de bem comum vem da interseção dos diversos interesses particulares que compõem a sociedade.

O problema de como podemos vir a conhecer a vg-padrão remete, no final das contas, à distância que separa a decisão do padrão e, portanto, ao problema das "deliberações públicas", que já foi evocado anteriormente. Como é bem conhecido, é para equacionar esse problema que Rousseau introduz a figura do Legislador (bem como alguns outros artifícios institucionais, a que voltaremos). É assim que Rousseau introduz a necessidade de um Legislador:

Como uma multidão cega, que frequentemente não sabe o que quer, porque raramente sabe o que é bom para ela, executaria por si mesma uma tarefa tão grande, tão difícil, quanto elaborar um sistema de legislação? Por si mesmo, o povo quer sempre o bem, mas, por si mesmo, não o vê sempre. A vontade geral é sempre reta, mas o juízo que a guia não é sempre esclarecido. 
É preciso fazê-la ver os objetos tal como eles são, algumas vezes tal como devem parecer, mostrar-lhe o bom caminho que ela procura, protegê-la da sedução das vontades particulares, aproximar de seus olhos os lugares e os tempos, equilibrar a atração das vantagens presentes e sensíveis com o perigo dos males afastados e escondidos. Os particulares vêem o bem que eles rejeitam, o público quer o bem que não vê. Todos precisam igualmente de guias. É preciso obrigar uns a conformar suas vontades à sua razão; é preciso ensinar ao outro a conhecer o que quer. Assim, das luzes públicas resulta a união do entendimento e da vontade no corpo social, daí o exato concurso das partes e, enfim, a maior força do todo. Eis de onde nasce a necessidade de um Legislador. (CS, III, 380).

Esse texto define uma das tarefas mais importantes do Legislador a tarefa que chamaremos aqui de "heurística" -, que é justamente a de dar uma formulação clara para este padrão de nossos juízos, que é a vg-padrão. Cabe ao Legislador encontrar uma formulação clara das condições que tornam possível a preservação do corpo social. Há um grau significativo de objetividade associado, por Rousseau, à ideia de bem comum: esse bem não é escolhido ou construído a partir de nossas decisões coletivas. Ao contrário, é condição de possibilidade dessas decisões mesmas. Enxergar - e fazer ver - esse bem comum é parte da tarefa grandiosa do Legislador. Isso é igualmente um dos pontos que justificam a sua excepcionalidade. Quando pinta o retrato do Legislador como homem extraordinário - carregando nas sugestões míticas e sobre-humanas - Rousseau está apenas destacando essa excepcionalidade de seu papel: o Legislador não tem função direta no processo de construção das decisões coletivas, embora sua tarefa de encontrar uma formulação especialmente clara da vg-padrão tenha efeitos profundos e duradouros na determinação das decisões coletivas, que constituem a vg-decisão.

Mas, como foi sublinhado, a ideia de bem comum inclui, além das condições de preservação do corpo social, o conjunto interseção composto pelos elementos comuns aos conjuntos de interesses particulares. Com isso em vista, podemos entender como a tarefa do Legislador está longe de se esgotar nessa tarefa heurística que foi apontada acima.

Rousseau parece ter adquirido, à medida que aprofundava sua compreensão dos princípios do direito político, uma consciência cada vez mais aguda da grande fragilidade da saúde dos corpos políticos. A liberdade é frágil: mantê-la indefinidamente é uma tarefa inglória, se não for impossível. Os corpos políticos estão fadados ao envelhecimento e à morte - e o que os corrói, por assim dizer, de dentro é o conflito potencialmente permanente entre interesses particulares e interesse geral. Do ponto de vista da legitimidade, aquela compreensão dos princípios políticos é suficiente. Do 
ponto de vista da estabilidade, aquela consciência da fragilidade pede mais. Isso leva Rousseau a reforçar consideravelmente o papel do Legislador

O segundo papel do Legislador vai ser justamente o de formador de interesses. Se o interesse comum deve ser visto, em algum sentido, como função dos interesses particulares (foi sugerido que o interesse geral está contido nos interesses particulares, constituindo-se como uma interseção desses últimos), então deve ser possível direcionar a construção do interesse comum agindo-se sobre (ou formando-se) os interesses particulares. Podemos partir, por exemplo, como horizonte máximo, da seguinte suposição: se o conjunto interseção dos interesses particulares tivesse uma extensão máxima, então não haveria diferença entre o interesse comum e os interesses particulares. Do ponto de vista rousseauniano, essa concordância perfeita do particular com o geral (uma espécie de reino da virtude) corresponde ao máximo de estabilidade. Dessa perspectiva, quanto mais larga for a superfície de interseção, tanto mais estável será a comunidade: quanto menores forem as diferenças (de valores, de crenças, de preferências), tanto menores serão as divisões, tanto mais facilmente será enxergado o padrão do bem comum - e, assim, tanto mais fácil será tomar as decisões coletivas. O papel do Legislador, dessa forma, é não apenas dar uma formulação, uma articulação visível do que seja o bem comum, mas, também, criar condições para que a interseção dos interesses seja a mais ampla possível. Esse é um papel que cabe excelentemente, por exemplo, à educação (lembremos aqui o espaço importante reservado por Rousseau à questão da educação, no Discours sur l'économie politique e nas Considérations sur le gouvernement de Pologne), como também aos festivais e festas públicas ${ }^{25}$, à censura, à religião civil, assim como a tudo o que visa a alimentar e reforçar o amour de la patrie ${ }^{26}$. Todas essas instituições prolongam o trabalho daquele Legislador mítico que Rousseau exemplifica, com alusões a Moisés, Licurgo e Numa - a tal ponto que poderíamos mesmo, quem sabe, identificar o Legislador, agora despersonalizado, com a atuação continuada desse conjunto de instituições, que agem direta ou indiretamente sobre os costumes e, a partir daí, sobre os próprios "corações".

\footnotetext{
${ }^{25}$ Jean Starobinski já chamava a atenção para o fato de que a exaltação da festa, em Rousseau, tem a mesma estrutura da vontade geral: "La description de la joie publique nous offre l'aspect lyrique de la volonté générale: c'est l'aspect qu'elle prende en habits du dimanche" (STAROBINSKI, 1971, p. 120).

${ }^{26}$ Em outro lugar, exploramos as relações entre os conceitos de vontade geral e amor à pátria. Ver REIS, 2005, p. 360.
} 
Como vimos, para Rousseau, o procedimento do sufrágio, que nos leva a conhecer a vontade geral (como decisão coletiva), tem um caráter claramente epistêmico. É, em suma, um procedimento voltado para a finalidade de selecionar a melhor resposta para a questão sobre o que é mais adequado (mais conforme) ao padrão do bem comum (independente das e anterior às decisões). Não é tanto um procedimento para descobrir o que é o bem comum, cujo conhecimento prévio, de resto, é condição para que o processo tenha confiabilidade, mas, como foi sugerido, um procedimento para escolher qual é a melhor interpretação desse bem comum, em um caso particular.

Ora, se é assim, esse procedimento só é necessário na medida em que existem, no seio da comunidade política, interpretações diferentes do que seja o bem comum. Pode parecer, pois, que o sufrágio é necessário justamente porque existe desacordo e esse desacordo precisa, de alguma maneira, encontrar uma solução (na forma de uma decisão coletiva).

Seria interessante perguntar-nos sobre a natureza desse desacordo (não se deve perder de vista que, para Rousseau, o bem comum, aquilo que é claramente percebido e conhecido pelo Legislador, existe independentemente de todo acordo ou desacordo e anteriormente a toda decisão coletiva). Esse desacordo pode ser resultado da própria natureza das coisas políticas: a complexidade da ideia de bem comum, sua relativa indeterminação e o conhecimento sempre incompleto que temos das circunstâncias justificam que um grau de desacordo exista e que, portanto, precisemos de um procedimento confiável para discernir, finalmente, qual posição é a melhor, segundo o padrão independente. Porém, se esse desacordo tiver raízes mais profundas, se for uma disputa não sobre qual é a melhor interpretação do bem comum que todos compartilhamos, mas uma competição entre diferentes concepções do que seja o bem comum, então o procedimento perde totalmente sua confiabilidade. Se a disputa diz respeito apenas sobre a melhor decisão, o procedimento tem boas chances de funcionar. Se se trata de uma disputa em torno do padrão, logo, Rousseau tende a pensar, tudo está perdido.

O trabalho do Legislador, por conseguinte, encontrando a formulação mais adequada (mais persuasiva) do padrão do bem comum, e o esforço de eliminação das condições daquele segundo tipo de desacordo mais profundo (esforço que, como sugerimos, dá continuidade e expande o trabalho do Legislador, por meio de instituições como a educação cívica, a censura e a religião civil) ganham, assim, uma importância capital e tornam-se condições sine qua non para o funcionamento de um regime democrático. Sem esse trabalho e esse esforço, seria impossível, no final das contas, ouvir a voz do povo nas decisões coletivas - voz que só se ouve, segundo Rousseau, sobre 
o fundo do grave silêncio proporcionado pelo acordo substantivo a que visa a atuação do Legislador.

Isso não deixa de ter consequências curiosas. Costumamos pensar no sufrágio como um momento especialmente significativo e importante de participação política (e isso parece amplificado, no modelo do Contrat social, já que o que está em jogo no processo de sufrágio é a própria atividade legislativa, exercida diretamente pelo povo). No entanto, se o trabalho do Legislador (incluindo aí a formulação do bem comum, que pode ser obra de um Legislador "personalizado", como nos mitos de fundação a que Rousseau tantas vezes se refere, e também o esforço continuado do Legislador "despersonalizado", na forma de instituições de educação, censura etc.) for bem feito, o sufrágio tende, no limite, a se tornar supérfluo ${ }^{27}$. Se ainda pode ser visto como necessário, dada a sua força epistêmica em um contexto de incerteza e indeterminação causadas pela complexidade das coisas políticas, como modo de participação política perde importância e, até mesmo, dado que está, finalmente, condicionado à existência de desacordos, acaba ganhando uma pequena sombra, que o empalidece diante da plenitude do acordo proporcionado pelo sucesso do Legislador.

É possível, enfim, ouvir a voz o povo? Rousseau acredita que sim. No entanto, se nos ativermos ao procedimento fundamental do sufrágio, teremos, efetivamente, pouco o que ouvir. Não é nos momentos do sufrágio que a voz do povo se deixa ouvir em toda a sua expressividade. A melodia que se exprime ali, na forma da vg-decisão, é pobre em comparação com o baixocontínuo, que é a vg-padrão. Se quisermos ouvir a voz do povo em toda a sua expressividade, parece sugerir Rousseau, não é nas assembleias políticas (orientadas para o sufrágio) que devemos procurar, mas nas festas, nos festivais públicos, nas atividades cívicas. Paradoxalmente, porém, nas condições mais ideais - e essas ocasiões cívicas talvez as reúnam melhor do que as situações em que o sufrágio do povo é solicitado -, o povo sequer

\footnotetext{
${ }^{27} \mathrm{~A}$ atitude de Rousseau com relação às assembleias populares muda entre a redação do $\mathrm{EP}$, quando acentuava as dificuldades práticas e a falta de necessidade de assembleias, quando o governo é "bem intencionado" (cf. III, 251), e o CS, quando vê as assembleias mais positivamente. De todo modo, permanece, mesmo quando vê as reuniões populares com melhores olhos, o medo (platônico) dos abusos a que pode ser submetido o povo, sempre bom, mas nem sempre virtuoso (como o próprio Jean-Jacques, de resto), o que o torna especialmente vulnerável à manipulação e ao engano. No CS, embora a percepção das assembleias seja mais positiva, permanece a desconfiança em torno dos debates públicos: se entendemos a deliberação pública na forma de um debate, estamos indo em direção de encontro à posição rousseauniana.
} 
precisa ter voz: ele pode muito bem se exprimir naquela linguagem secreta, inefável, sem palavras e sem voz, que Rousseau evoca sem cessar, nas Confessions, na Nouvelle Heloïse e em outras obras - a mesma linguagem, talvez, que deva utilizar o Legislador para persuadir sem convencer. Se tudo isso decorre, em boa parte, de certas idiossincrasias rousseaunianas, nem por isso deixa de ter importância para pensarmos com mais nitidez sobre o alcance e as implicações de algumas de nossas crenças e de alguns de nossos compromissos democráticos.

REIS, Cláudio Araújo. General will and collective decision in Rousseau.Trans/Form/Ação, (Marília); v.33, n.2, p.11-34, 2010

ABSTRACT: In rousseauian terms, the fundamental question about what we should collectively do (i.e., the problem of collective decision-making) translates itself as the question about how we could know what the general will is. This question, however, can only be adequately answered if we consider that "general will" has a double meaning. Rousseau uses the same expression to refer to two quite different things: to the collective decisions themselves consubstantiated in the law ("gw-as a decision") and to the common good as a pattern which, in a way, exists before and independently of the decisions, functioning as a reference to the decision-making procedure ("gw-as a pattern"). The general question about how could we know what the general will is, then, should be split into two: How can we get to know the gw-as a decision? and How can we get to know the gw-as a pattern? This article intends to identify the central elements of Rousseau's answer to this two questions, which throw an interesting light on the rousseauian conception of democracy.

KEYWORDS: Jean-Jacques Rousseau. Democracy. Collective decision. General will.

\section{REFERÊNCIAS}

Abreviaturas utilizadas (obras de Rousseau):

CS - Contrat social

EP - Discours sur l'économie politique

MG - Manuscrit de Genève (primeira versão do Contrat social)

ALLEN, Glen. La volonté de tous and la volonté générale: a distinction and its significance. Ethics, v. 71, n. 4, p. 263-275, 1961.

BERNARDI, Bruno. Volonté générale, interêt, bien commun (sur la formation du concept de volonté generale dans la philosophie politique de Jean-Jacques Rousseau). Cahiers Philosophiques, v. 77, p. 75-106, 1998. 
BRIAN, B. M.; REES, W. J. The public interest. Proceedings of the Aristotelian Society, v. 38, p. 1-38, 1964. Supplementary Volumes.

COHEN, Joshua. An epistemic conception of democracy. Ethics, v. 97, n. 1, p. 26-38, 1986a.

COHEN, Joshua. Reflections on Rousseau: autonomy and democracy. Philosophy and Public Affairs, v. 15, n. 3, p. 275-297, 1986b.

DUMONT, Louis. Homo Hierarchicus. Paris: Gallimard, 1966.

DUMONT, Louis. Homo Aequalis. Paris: Gallimard, 1977.

DUMONT, Louis. Essais sur l'individualisme. Paris: Seuil, 1983.

ESTLUND, David et al. Democratic theory and public interest: Condorcet and Rousseau revisited. The American Political Science Review, v. 83, n. 4, p. 13171340, 1989

ESTLUND, David. Democratic authority: a philosophical framework. Princeton: Princeton UP, 2008.

FAVRE, Pierre. Unanimité et majorité dans le Contrat social de Jean-Jacques Rousseau. Revue du Droit Public et de la Science Politique de la France et de l'Étranger, v. 92, n. 1, p. 111-186, 1976.

GAUS, Gerald. Does democracy reveal the voice of the people? Four takes on Rousseau. Australasian Journal of Philosophy, v. 75, n. 2, p. 141-162, 1997.

GRAHAM JUNIOR, George. Rousseau's concept of consensus. Political Science Quarterly, v. 85, n. 1, p. 80-98, 1970.

GROFMAN, Bernard; FELD, Scott. Rousseau's general will: a condorcetian perspective. The American Political Science Review, v. 82, n. 2, p. 567-576, 1988.

MANIN, Bernard. Volonté générale ou délibération: esquisse d'une théorie générale de la délibération politique. Le Débat, v. 33, p. 72-93, 1985.

PUTTERMAN, Ethan. Rousseau on agenda-setting and majority rule. The American Political Science Review, v. 97, n. 3, p. 459-469, 2003.

PUTTERMAN, Ethan. Rousseau on the people as legislative gatekeepers, not framers. The American Political Science Review, v. 99, n. 1, p. 145-151, 2005.

RAWLS, John. Lectures on the history of political philosophy. Cambridge: Harvard UP, 2007.

REIS, Claudio. Unidade e liberdade: o indivíduo segundo Jean-Jacques Rousseau. Brasília: UnB, Finatec, 2005

RIKER, William. Liberalism against populism: a confrontation between the theory of democracy and the theory of social choice. San Francisco: W. H. Freeman, 1982. 
RILEY, Patrick. Will and political legitimacy. Cambridge: Harvard UP, 1982.

RILEY, Patrick. Rousseau's general will. In: RILEY, Patrick (Ed.). The Cambridge Companion to Rousseau. Cambridge: Cambridge UP, 2006.

ROUSSEAU, Jean-Jacques. Oeuvres completes. Paris: Gallimard, 1959-1995. 5 v.

SCHWARTZENBERG, Melissa. Voting the general will: Rousseau on decision rules. Political Theory, v. 36, n. 3, p. 403-423, 2008.

SCOTT, John. Rousseau's Anti-agenda setting agenda and contemporary democratic theory. The American Political Science Review, v. 99, n. 1, p. 137144, 2005.

SHKLAR, Judith. Men and citizens: a study of rousseau's social theory. Cambridge: Cambridge UP, 1969.

SREENIVASAN, Gopal. "What is the general will?" The Philosophical Review, v. 109, n. 4, p. 545-581, 2000.

STAROBINSKI, Jean. Jean-Jacques Rousseau: la transparence et l'obstacle. Paris: Gallimard, 1971. 